\title{
Vitamin C decreases VEGF expression levels via hypoxia-inducible factor-1 $\alpha$ dependent and independent pathways in lens epithelial cells
}

\author{
LIN ZHAO, JIANMING WANG，YI ZHANG，LIJUN WANG，MIAO YU and FENG WANG
}

Department of Ophthalmology, The Second Affiliated Hospital, Xi'an Jiaotong University, Xi'an, Shaanxi 710004, P.R. China

Received August 28, 2019; Accepted March 27, 2020

DOI: $10.3892 / \mathrm{mmr} .2020 .11103$

\begin{abstract}
Posterior capsular opacification (PCO) is the main complication following cataract surgery. The proliferation of the residual lens epithelial cells (LECs) serves an important role in PCO formation. The authors' previous study revealed that vitamin $\mathrm{C}$ inhibited the proliferation of human LECs by increasing the rapid degradation of hypoxia-inducible factor-1 (HIF-1 $\alpha$ ), and hence inhibited the expression of vascular endothelial growth factor (VEGF). The present study aimed to further investigate the mechanisms underlying the effects of vitamin $\mathrm{C}$ on the expression levels of VEGF. The present study demonstrated that the HIF-1 inhibitor BAY 87-2243 significantly inhibited the cell proliferation and the expression levels of VEGF in LECs through the use of colony formation, western blotting and ELISA assays. Moreover, it was revealed that vitamin $\mathrm{C}$ could further inhibit the cell proliferation and the expression levels of VEGF in LECs following the cotreatment with the HIF-1 inhibitor. The proline hydroxylation of HIF-1 $\alpha$ by prolyl hydroxylases (PHDs) was previously discovered to be responsible for the rapid degradation of HIF- $1 \alpha$. Thus, the present study subsequently used three PHD inhibitors to investigate their effects on the expression levels of VEGF; it was found that the PHD2 specific inhibitor increased the expression levels of VEGF to the greatest extent. Moreover, the genetic knockdown of PHD2 by lentiviral transfection also significantly increased the expression levels of VEGF, whereas the PHD2 specific inhibitor did not alter the expression levels of VEGF in the PHD2 knockdown LECs. AKT kinase activity is an important mediator known to upregulate VEGF expression. Using an immunoprecipitation assay to isolate endogenous AKT, it was demonstrated that AKT was prolyl hydroxylated by PHD2, which inhibited its activity. It was also revealed that vitamin C
\end{abstract}

Correspondence to: Dr Feng Wang, Department of Ophthalmology, The Second Affiliated Hospital, Xi'an Jiaotong University, 3 Shang Qin Road, Xincheng, Xi'an, Shaanxi 710004, P.R. China

E-mail: fengwong029@gmail.com

Key words: posterior capsular opacification, vitamin C, vascular endothelial growth factor, hypoxia-inducible factor- $1 \alpha$, AKT, proline hydroxylation, prolyl hydroxylase protein 2 enhanced the proline-hydroxylation and inhibited the activity of AKT. Furthermore, an AKT inhibitor increased the effects of vitamin $\mathrm{C}$ on the expression levels of VEGF. However, the AKT inhibitor did not affect the expression levels of glucose transporter 1 , which is a HIF-1 $\alpha$ target gene. In conclusion, the findings of the present study suggested that vitamin $\mathrm{C}$ may inhibit the expression levels of VEGF via HIF-1 $\alpha$-dependent and AKT-dependent pathways in LECs.

\section{Introduction}

Posterior capsular opacification (PCO) is the main complication following cataract surgery and it is a leading cause of visual impairment worldwide $(1,2)$. While there has been an improvement in surgical techniques and intraocular lens material, the incidence of PCO remains high in $15-50 \%$ of patients within $2-5$ years following cataract surgery $(3,4)$. The proliferation of residual lens epithelial cells (LECs) serves an important role in PCO formation; residual LECs have been discovered to regenerate within a few hours following cataract surgery, before migrating across the posterior capsule $(5,6)$. Thus, inhibiting the proliferation of LECs may be an important therapeutic strategy for $\mathrm{PCO}$ prevention in clinical practice.

High levels of vitamin $C$ intake have been revealed to serve beneficial effects in preventing age-related cataracts or PCO formation following cataract surgery (7-10). In addition, the long-term supplement use of vitamin $\mathrm{C}$ has been inversely associated with the occurrence of cataracts or PCO risk $(11,12)$. Hypoxia-inducible factor- $1 \alpha$ (HIF-1 $\alpha)$ and vascular endothelial growth factor (VEGF) have also been discovered to serve important roles in the stimulation of cell proliferation and migration; VEGF is a target gene of the HIF-1 $\alpha$ and the upregulation of the HIF-1 $\alpha /$ VEGF signaling axis was identified to promote cell proliferation and migration $(13,14)$. The proline hydroxylation of HIF-1 $\alpha$ by prolyl hydroxylases (PHDs) is responsible for the rapid degradation of HIF-1 $\alpha(15,16)$. Notably, vitamin $\mathrm{C}$ has been identified to serve as a cofactor of PHDs (17). The authors' previous study demonstrated that vitamin $\mathrm{C}$ inhibited the proliferation of human LECs by enhancing the rapid degradation of HIF-1 $\alpha$ via proline hydroxylation and thus, inhibited the expression levels of VEGF (10).

The present study aimed to investigate the molecular mechanisms of vitamin $\mathrm{C}$ on the expression levels of VEGF in 
more detail. The findings of the present study demonstrated that the HIF-1 inhibitor BAY 87-2243 significantly inhibited cell proliferation and VEGF expression levels in LECs. Moreover, vitamin $\mathrm{C}$ further inhibited the proliferation and expression levels of VEGF in LECs following the treatment with the HIF-1 inhibitor. These findings suggested that vitamin $\mathrm{C}$ may inhibit VEGF expression levels via both HIF-1 $\alpha$-dependent and -independent pathways in LECs.

\section{Materials and methods}

Cell culture. The human LEC line HLE-B3 was purchased from the American Type Culture Collection and the 293T cell line was obtained from the Cell Bank of Type Culture Collection of the Chinese Academy of Sciences. Both cells were cultured in DMEM (Gibco; Thermo Fisher Scientific, Inc.), supplemented with 10\% FBS (Gibco; Thermo Fisher Scientific, Inc.), and maintained in a humidified atmosphere at $37^{\circ} \mathrm{C}$ and $5 \% \mathrm{CO}_{2}$.

Reagents. Primary antibodies against glucose transporter 1 (GLUT1; 1:2,000; cat. no. 12939), lysine-specific demethylase 1 (LSD1; 1:2,000; cat. no. 2184), HIF-1 $\alpha$ (1:1,1000; cat. no. 36169), PHD2 (1:3,000; cat. no. 4835), AKT (1:2,000; cat. no. 2938) and phosphorylated (p)-T308-AKT (1:1,000; cat. no. 13038) were purchased from Cell Signaling Technology, Inc. Primary antibodies against $\beta$-actin (1:5,000; cat. no. ab16039), VEGF $(1: 1,000$; cat. no. ab46154) and hydroxyproline (1:500; cat. no. ab37067; for detecting prolyl hydroxylated AKT) were purchased from Abcam. The horseradish peroxidase-conjugated secondary antibody (1:5,000; cat. no. ab205718) was obtained from Abcam and normal rabbit IgG (1:500; cat. no. 2729) was purchased from Cell Signaling Technology, Inc. Vitamin C (100 $\mu \mathrm{M}$; cat. no. 95209) and dimethyloxaloylglycine (DMOG; $1 \mathrm{mM}$; cat. no. D3695) were obtained from Sigma-Aldrich; Merck KGaA. The PHD2 selective inhibitor IOX2 (10 $\mu \mathrm{M}$; cat. no. 9451) and AKT inhibitor A-674563 (5 $\mu \mathrm{M}$; cat. no. B1761) were purchased from BioVision, Inc. The HIF-1 inhibitor BAY 87-2243 (100 nM; cat. no. B1115) was from APeXBIO Technology LLC and the PHD inhibitor Molidustat ( $5 \mu \mathrm{M}$; cat. no. S8138) was obtained from Selleck Chemicals. The above drugs were used to treat HLE-B3 cells at $37^{\circ} \mathrm{C}$.

Lentiviral transfection. PHD2 short hairpin RNA (shRNA/sh) targeting sequences (sh1, 5'-CGCAATAACTGTTTGGTA TTT-3'; and sh2, 5'-CTGTTATCTAGCTGAGTTCAT-3') and a scramble control (5'-CCTAAGGTTAAGTCGCCCTCGCTC GAGCGAGGGCGACTTAACCTTAGG-3') were cloned into a pLKO.1 lentiviral knockdown vector (Open Biosystems, Inc.). Lentiviral expression vectors (pCDH-CMV-MCS-EF1-Puro; System Biosciences, LLC) expressing wild-type (WT) AKT and hydroxylation-deficient mutants of AKT (AKT-P125/313A) were purchased from GrowHealthy. A total of $5 \times 10^{6} 293 \mathrm{~T}$ cells were transfected with $12 \mu \mathrm{g}$ plasmids using Lipofectamine ${ }^{\circledR}$ 3000 reagent (Thermo Fisher Scientific, Inc.). Lentiviral vectors were produced in $293 \mathrm{~T}$ cells with packaging plasmids according to our previous study (14). Following incubation for $48 \mathrm{~h}$ at $37^{\circ} \mathrm{C}$, the lentivirus supernatants were harvested and transfected into $1 \times 10^{6}$ HLE-B3 cells in the presence of $8 \mu \mathrm{g} / \mathrm{ml}$ polybrene [cat. no. 28728-55-4; Sigma-Aldrich (Merck
KGaA)]. Following incubation with puromycin-containing media for $72 \mathrm{~h}$, the expression levels of target proteins were analyzed using western blotting.

Reverse transcription-quantitative PCR (RT-qPCR). Total RNA was extracted from cells using the RNeasy Mini kit (cat. no. 74106; Qiagen, Inc.), according to the manufacturer's protocol. Total RNA was reverse transcribed into cDNA using a PrimeScript ${ }^{\mathrm{TM}}$ RT reagent kit (Takara Bio, Inc.), according to the manufacturer's protocol, for $1 \mathrm{~h}$ at $37^{\circ} \mathrm{C}$. qPCR was subsequently performed using SYBR Green I dye (Takara Bio, Inc.), according to the manufacturer's protocol. The following thermocycling conditions were used for the qPCR: $95^{\circ} \mathrm{C}$ for $15 \mathrm{~min}$; followed by 40 cycles of $94^{\circ} \mathrm{C}$ for $15 \mathrm{sec}, 55^{\circ} \mathrm{C}$ for $30 \mathrm{sec}$ and $70^{\circ} \mathrm{C}$ for $30 \mathrm{sec}$; and a final extension step at $72^{\circ} \mathrm{C}$ for $5 \mathrm{~min}$. The following primer pairs were used for the qPCR: VEGF forward, 5'-TGCAGATTATGCGGATCAAACC-3' and reverse, 5'-TGC ATTCACATTTGTTGTGCTGTAG-3'; and $\beta$-actin forward, 5'-GAGCACAGAGCCTCGCCTTT-3' and reverse, 5'-AGA GGCGTACAGGGATAGCA-3'. Relative mRNA expression levels were quantified using the $2^{-\Delta \Delta \mathrm{Cq}}$ method (18) and normalized to $\beta$-actin as the endogenous control.

Immunoprecipitation assay. A total of $1 \times 10^{7}$ cells were lysed with $1 \mathrm{ml} \mathrm{NP40} \mathrm{lysis} \mathrm{buffer} \mathrm{(Beyotime} \mathrm{Institute} \mathrm{of}$ Biotechnology). Following centrifugation at $16,500 \mathrm{x} \mathrm{g}$ for $20 \mathrm{~min}$ at $4^{\circ} \mathrm{C}$, cell lysates were pre-cleared with $40 \mu 1$ Protein A/G beads alone (cat. no. sc-2003; Santa Cruz Biotechnology, Inc.) for $1 \mathrm{~h}$ at $4^{\circ} \mathrm{C}$ to reduce the non-specific protein binding. The pre-cleared cell lysates were subsequently incubated with an anti-AKT antibody (1:500) to isolate total AKT protein or normal rabbit IgG (1:500) as the negative control for $3 \mathrm{~h}$ at $4^{\circ} \mathrm{C}$ and then with $40 \mu \mathrm{l}$ protein $\mathrm{A} / \mathrm{G}$ agarose beads overnight at $4^{\circ} \mathrm{C}$. Following the incubations, protein $\mathrm{A} / \mathrm{G}$ agarose beads were washed with NP40 buffer five times and the immunoprecipitated samples were eluted from protein $\mathrm{A} / \mathrm{G}$ agarose beads with $40 \mu 11 \mathrm{X} \mathrm{SDS}$ sample buffer by heating at $100^{\circ} \mathrm{C}$ for $5 \mathrm{~min}$. Following centrifugation at $3,650 \mathrm{x}$ g for $1 \mathrm{~min}$ at $4^{\circ} \mathrm{C}$, the proteins ( $20 \mu \mathrm{l}$ from the total $40 \mu \mathrm{l}$ sample) were analyzed using western blotting. The expression levels of immunoprecipitated endogenous prolyl hydroxylated AKT (pro-AKT) were detected using an anti-hydroxyproline antibody, as described below.

Western blotting. Total protein was extracted from cells using RIPA lysis buffer containing a protease/phosphatase inhibitors mixture (Beyotime Institute of Biotechnology). Nuclear proteins were extracted using a nucleoprotein extraction kit (cat. no. BB-3102-1; BestBio Co. Ltd.), according to the manufacturer's protocol. Total protein was quantified using the Bradford method and $50 \mu \mathrm{g}$ protein/lane was separated via $10 \%$ SDS-PAGE. The separated proteins were subsequently transferred onto PVDF membranes (EMD Millipore) and blocked with 5\% BSA (Beijing Solarbio Science \& Technology Co., Ltd.) in TBS-0.1\% Tween (TBST) buffer (Thermo Fisher Scientific, Inc.) at $37^{\circ} \mathrm{C}$ for $1 \mathrm{~h}$. The membranes were then incubated with the following primary antibodies at $4^{\circ} \mathrm{C}$ overnight: Anti-GLUT1, anti-LSD1, anti-HIF-1 $\alpha$, anti-PHD2, anti-AKT, anti-p-T308-AKT, anti- $\beta$-actin, anti-VEGF and anti-hydroxyproline. Following the primary antibody incubation, the 

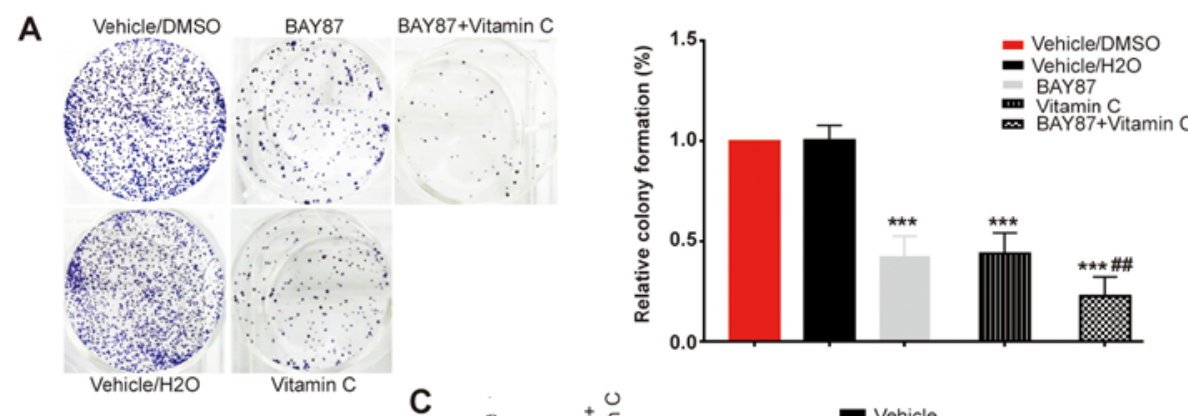

B
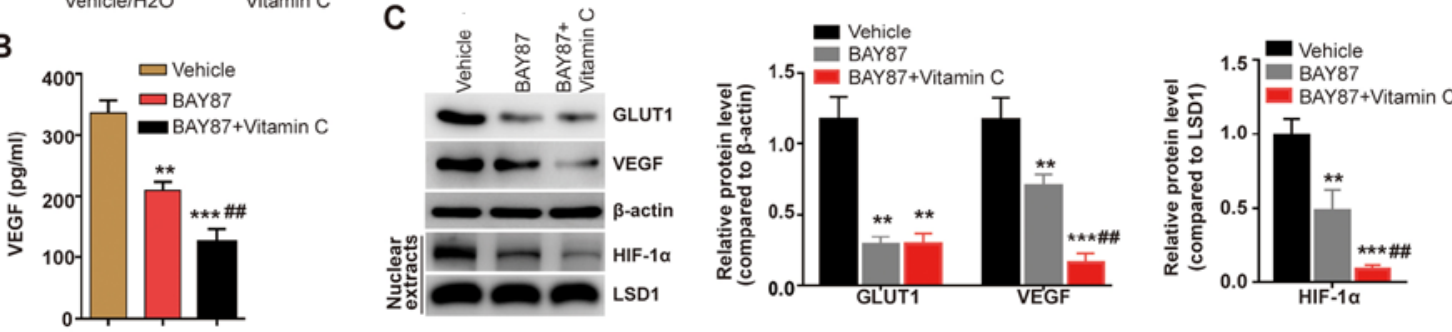

Figure 1. Vitamin C inhibits the proliferation of HLE-B3 cells and VEGF expression levels. (A) Colony formation assays were performed to determine the proliferation rate of HLE-B3 cells treated with vehicle (DMSO), $100 \mathrm{nM}$ BAY 87 or $100 \mathrm{nM}$ BAY 87 and $100 \mu \mathrm{M}$ vitamin C for 12 days. Data are presented as the mean \pm SD of 3 independent experiments. (B) Secretion of VEGF from HLE-B3 cells was detected using an ELISA. Data are presented as the mean \pm SD of 3 independent experiments. (C) Western blotting was used to determine the expression levels of GLUT1, VEGF and HIF-1 $\alpha$ in whole-cell or nuclear extracts following the treatment with vehicle (DMSO), $100 \mathrm{nM}$ BAY 87 or $100 \mathrm{nM} \mathrm{BAY} 87$ and $100 \mu \mathrm{M}$ vitamin C for $12 \mathrm{~h}$. Data are presented as the mean \pm SD of 3 independent experiments. VEGF, vascular endothelial growth factor; GLUT1, glucose transporter 1; HIF-1 $\alpha$, hypoxia inducible factor $1 \alpha$; LSD1, lysine-specific histone demethylase 1; BAY-87, BAY 87-2243. ${ }^{* *} \mathrm{P}<0.01,{ }^{* * *} \mathrm{P}<0.001$ vs. vehicle group; ${ }^{\# \#} \mathrm{P}<0.01$ vs. BAY 87 group.

membranes were washed thrice with PBST buffer and incubated with the horseradish peroxidase-conjugated secondary antibody at $37^{\circ} \mathrm{C}$ for $1 \mathrm{~h}$. Protein bands were detected using an ECL ${ }^{\mathrm{TM}}$ Western Blotting Detection reagent (GE Healthcare Life Sciences) and the expression levels were quantified using ImageJ version $1.47 \mathrm{v}$ software (National Institutes of Health). Each experiment was independently repeated three times.

Colony formation assay. A total of $2.5 \times 10^{2}$ HLE-B3 cells/well were plated into $6-\mathrm{cm}$ well plates and incubated for $24 \mathrm{~h}$. Cells were subsequently treated with the DMSO vehicle control [equal volume to the inhibitor; Sigma-Aldrich (Merck KGaA)] or different inhibitors (100 nM BAY 87-2243100; $100 \mu \mathrm{M}$ vitamin C; $5 \mu \mathrm{M} \mathrm{A}-674563)$ at $37^{\circ} \mathrm{C}$ for 12 days. Following the incubation, cells were fixed with $75 \%$ ethanol at $37^{\circ} \mathrm{C}$ for $15 \mathrm{~min}$ and then stained with $0.01 \%$ crystal violet at $37^{\circ} \mathrm{C}$ for $30 \mathrm{~min}$ and visualized. The relative colony formation rate (\%) was determined using the following equation: (Number of colonies formed from drug-treated cells/number of colonies formed from untreated cells) x100.

ELISA. An ELISA was used to detect the secretory levels of VEGF in HLE-B3 cells. Briefly, a total of $1 \times 10^{6} \mathrm{HLE}-\mathrm{B} 3$ cells were treated with DMSO vehicle, $100 \mathrm{nM}$ BAY 87-2243100 or $100 \mathrm{nM}$ BAY $87-2243100$ and $100 \mu \mathrm{M}$ vitamin $\mathrm{C}$ at $37^{\circ} \mathrm{C}$ for $12 \mathrm{~h}$. Following centrifugation of 2,000 $\mathrm{x}$ f for $20 \mathrm{~min}$ at room temperature, cell culture supernatants were collected. VEGF levels were measured using a Human VEGF Quantikine ELISA kit (cat. no. DVE00; R\&D Systems, Inc.) according to the manufacturer's protocol.

Statistical analysis. Statistical analysis was performed using GraphPad Prism 7.0 software (GraphPad Software, Inc.) and data are expressed as the mean $\pm \mathrm{SD}$ of three independent experiments. Statistical differences between two groups were analyzed by a two-tailed Student's t-test, whereas a one-way ANOVA followed by a Tukey's multiple comparison test was used for multiple groups. $\mathrm{P}<0.05$ were considered to indicate a statistically significant difference.

\section{Results}

Vitamin $C$ inhibits cell proliferation and VEGF expression levels following HIF-1 inhibition. Our previous study revealed that vitamin $\mathrm{C}$ inhibited cell proliferation and VEGF expression levels (10). Vitamin C, an essential cofactor of PHDs, has been discovered to increase the proline hydroxylation of HIF- $1 \alpha$, thus promoting the degradation of HIF-1 $\alpha$ via the ubiquitin-proteasome pathway (17). Therefore, it was hypothesized that HIF-1 $\alpha$ may serve a crucial role in vitamin C-inhibited LEC proliferation. The present study used a HIF-1 inhibitor (BAY 87-2243) to investigate the effect of vitamin C in HLE-B3 LECs. While the proliferation of HLE-B3 cells was significantly inhibited following the treatment with BAY 87-2243 compared with the vehicle group, the combined treatment of BAY 87-2243 with vitamin C was found to further inhibit the proliferation of LECs compared with the BAY 87-2243 group (Fig. 1A).

GLUT1 and VEGF, which both possess hormone response elements, are well-known targets of HIF-1 $\alpha$ (19). Thus, the present study analyzed the expression levels of GLUT1 and the secretion of VEGF in the presence of BAY 87-2243 and vitamin C. It was found that BAY 87-2243 significantly inhibited the expression levels of GLUT1 and the secretion of VEGF compared with the vehicle group (Fig. 1B and C). However, whilst the combined treatment of BAY 87-2243 and vitamin $C$ further inhibited VEGF expression levels and secretion in HLE-B3 cells, the expression levels of GLUT1 were not 

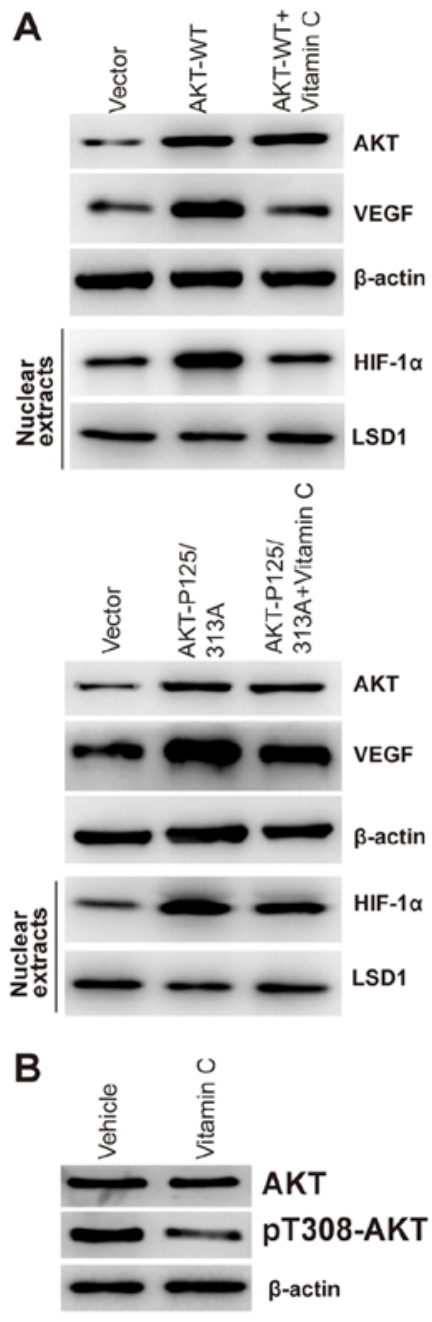
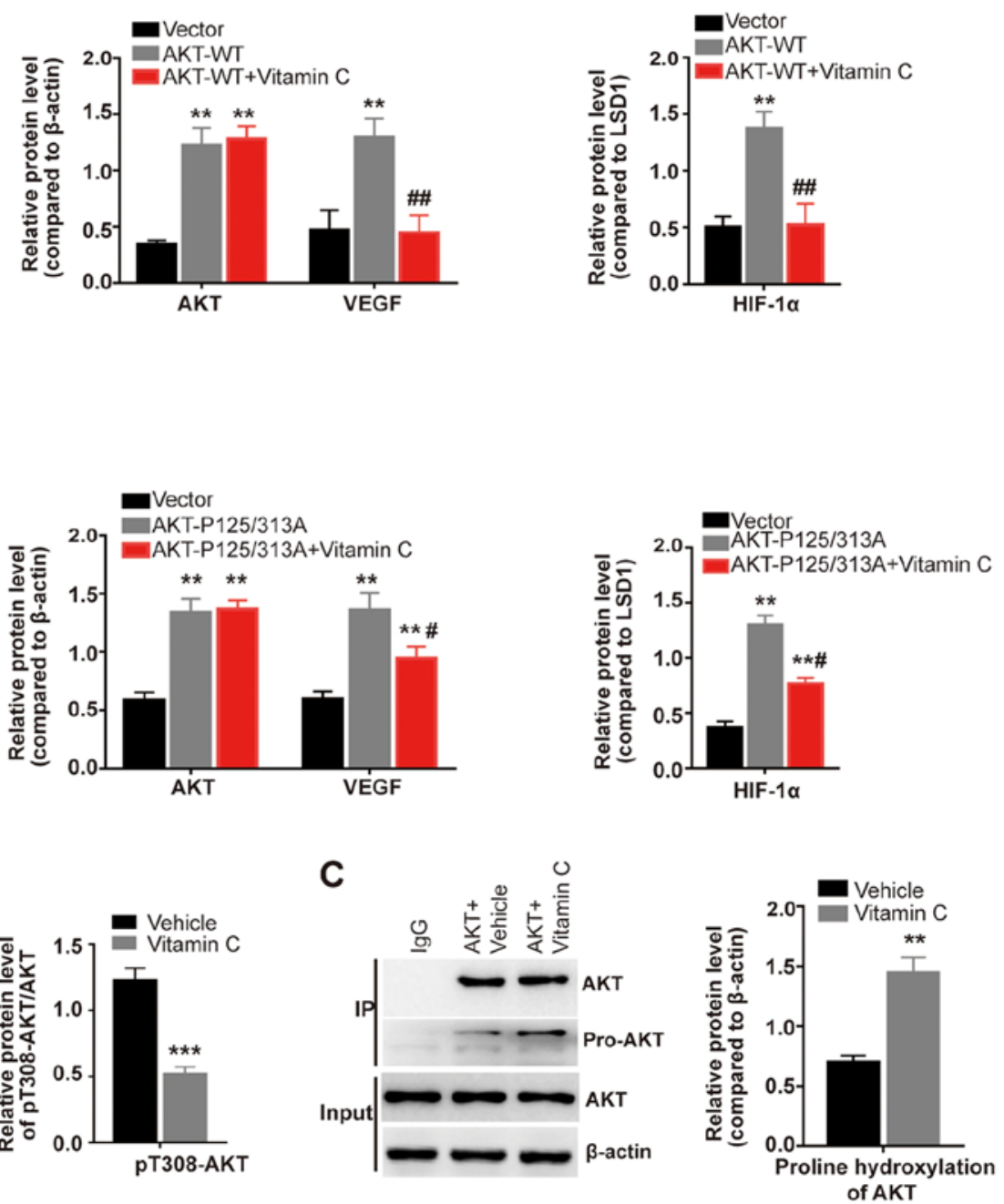

Figure 2. Vitamin C inhibits the activity of AKT by increasing its proline hydroxylation. (A) Expression levels of AKT, VEGF and HIF-1 $\alpha$ protein from whole-cell or nuclear extracts were determined using western blotting in AKT-WT or proline-mutant AKT-P125/313A overexpressing HLE-B3 cells treated with or without $100 \mu \mathrm{M}$ vitamin $\mathrm{C}$ for $12 \mathrm{~h}$. Data are presented as the mean \pm SD for 3 independent experiments. (B) Expression levels of AKT and pT308-AKT were determined using western blotting in HLE-B3 cells treated with vehicle $\left(\mathrm{H}_{2} \mathrm{O}\right)$ or $100 \mu \mathrm{M}$ vitamin $\mathrm{C}$ for $12 \mathrm{~h}$. Data are presented as the mean $\pm \mathrm{SD}$ of 3 independent experiments. (C) HLE-B3 cells were treated with or without $100 \mu \mathrm{M}$ vitamin C for $12 \mathrm{~h}$ and subjected to immunoprecipitation with an IgG or AKT antibody. Expression levels of immunoprecipitated endogenous AKT and pro-AKT (prolyl hydroxylated AKT detected by anti-hydroxyproline antibody) were analyzed using western blotting. Data are presented as the mean \pm SD of 3 independent experiments. VEGF, vascular endothelial growth factor; HIF-1 $\alpha$, hypoxia inducible factor $1 \alpha$; LSD1, lysine-specific histone demethylase 1; WT, wild-type; pT308, phosphorylated on Tyrosine 308; NC, negative control. ${ }^{* *} \mathrm{P}<0.01,{ }^{* * * *} \mathrm{P}<0.001$ vs. vehicle or vector group; ${ }^{\# \mathrm{P}}<0.05,{ }^{\# \#} \mathrm{P}<0.01$ vs. AKT-WT/AKT-P125/313A groups.

further affected by vitamin C (Fig. 1B and C). Although the HIF-1 $\alpha$ protein is rapidly degraded by the ubiquitin-proteasome pathway under normoxic conditions (20), HIF-1 $\alpha$ can be detected from isolated nuclear extracts under normoxic conditions $(21,22)$. In the present study, it was revealed that vitamin C demonstrated a synergistic effect with BAY $87-2243$ by decreasing the expression levels of HIF-1 $\alpha$ compared with the vehicle and to a further extent compared with the BAY 87-2243 group (Fig. 1C). Therefore, the present results suggested that vitamin $\mathrm{C}$ may inhibit VEGF expression levels via HIF-1 $\alpha$ dependent and independent pathways in LECs.

Vitamin $C$ increases proline hydroxylation and inhibits the activity of AKT. The activation of the serine/threonine-specific protein kinase AKT has been found to promote the proliferation of various types of cancer (23). AKT activation is involved in mediating VEGF upregulation (24). Furthermore, AKT is prolyl-hydroxylated by the oxygen-dependent prolyl hydroxylase PHD2 (25). The present results observed that the overexpression of AKT-WT significantly increased the expression levels of VEGF compared with the vector group (Fig. 2A). Notably, following the treatment with vitamin C, the increased expression levels of VEGF observed in the AKT-WT group were significantly decreased compared with the AKT-WT group (Fig. 2A). It has been reported that proline at position 125 or 313 of AKT can be hydroxylated by PHD2, which leads to aberrant AKT activation (25). The present study used a hydroxylation-deficient mutant of AKT by replacing proline at position 125 and 313 with alanine (P125/313A). While AKT-P125/313A overexpression significantly increased the expression levels of VEGF compared with the vector group, vitamin $\mathrm{C}$ treatment significantly 
A
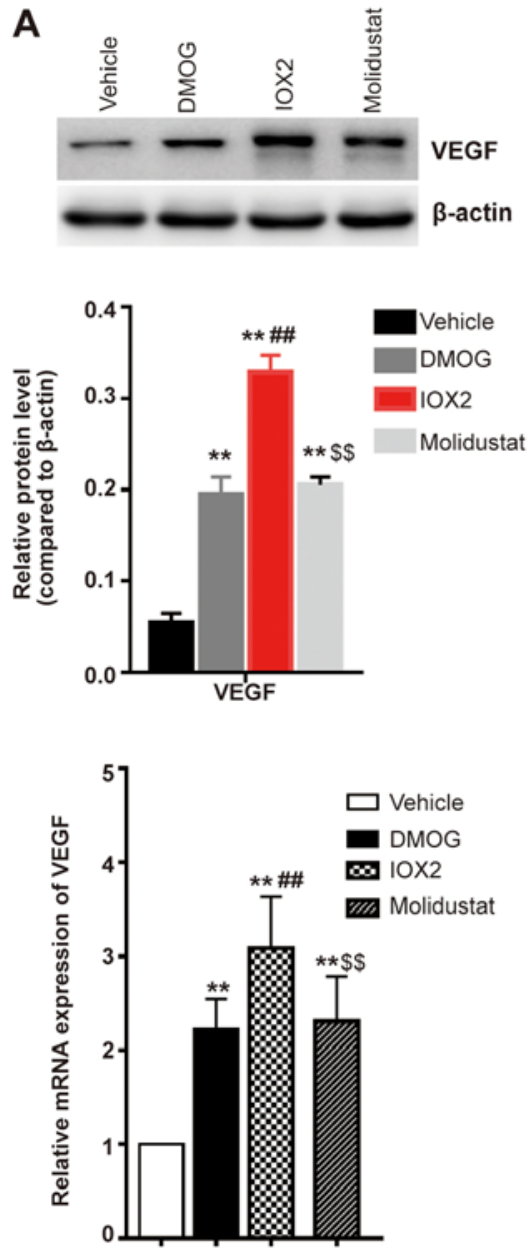

B
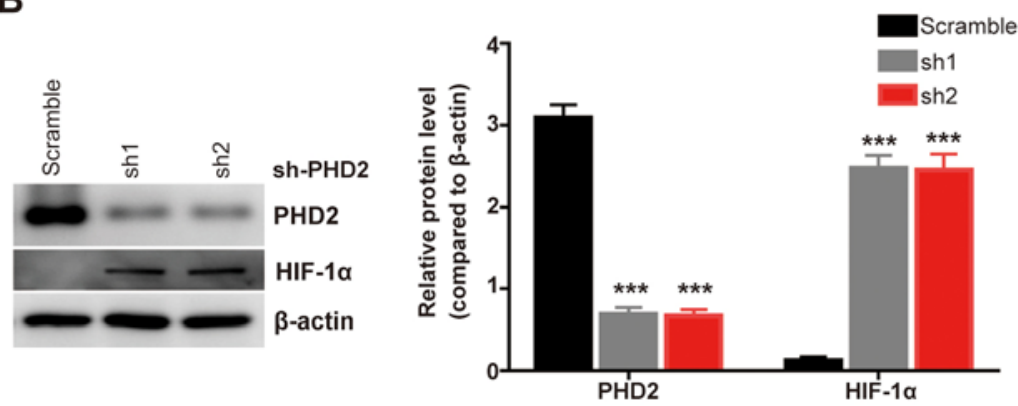

C
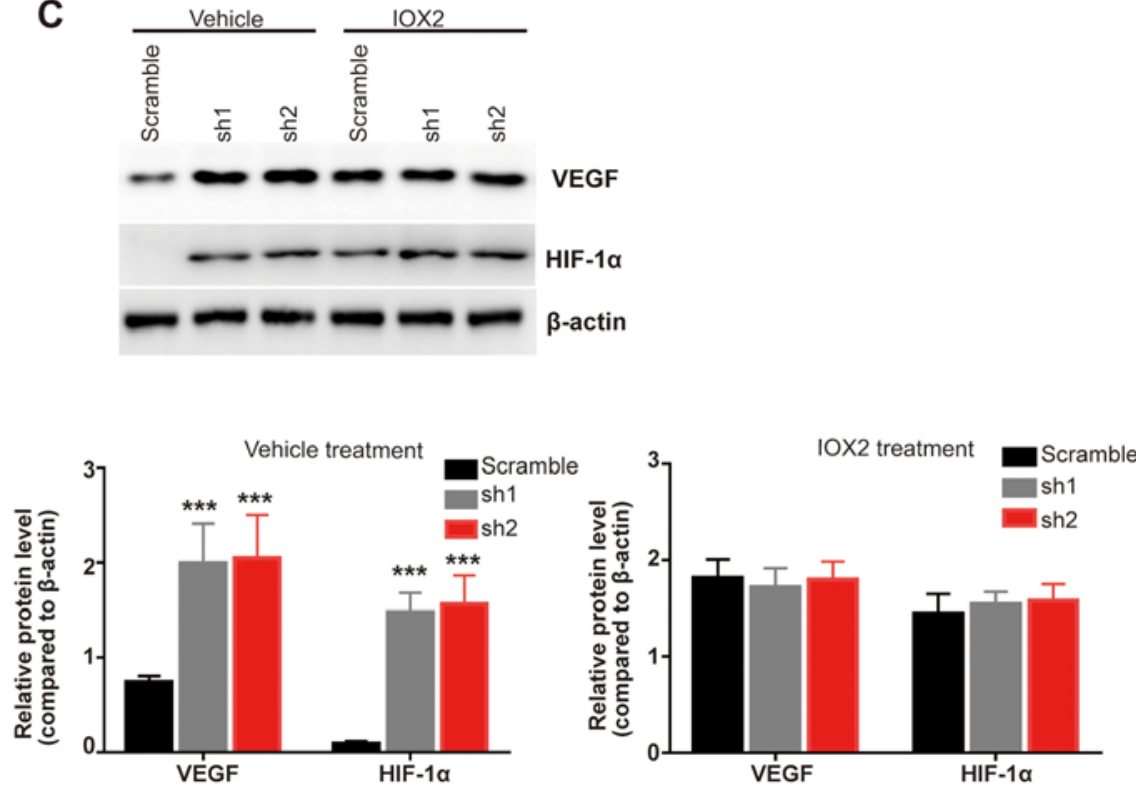

Figure 3. Inhibition of PHD2 increases VEGF expression levels. (A) VEGF expression levels were analyzed using western blotting and reverse transcription-quantitative PCR in HLE-B3 cells treated with vehicle (DMSO), $1 \mathrm{mM}$ DMOG, $10 \mu \mathrm{M}$ IOX2 or $5 \mu \mathrm{M}$ Molidustat for $12 \mathrm{~h}$. Data are presented as the mean \pm SD of 3 independent experiments. (B) Expression levels of PHD2 and HIF-1 $\alpha$ were analyzed using western blotting in PHD2 knockdown (sh1 and sh2) HLE-B3 cells. Data are presented as the mean \pm SD of 3 independent experiments. (C) Scramble control and PHD2 knockdown HLE-B3 cells were treated with vehicle (DMSO) or $10 \mu \mathrm{M}$ IOX 2 or $12 \mathrm{~h}$ and the expression levels of HIF-1 $\alpha$ and VEGF proteins were analyzed using western blotting. Data are presented as the mean \pm SD of 3 independent experiments. PHD2, prolyl hydroxylase 2; VEGF, vascular endothelial growth factor; DMOG, dimethyloxaloylglycine; sh, short hairpin RNA; HIF-1 $\alpha$, hypoxia inducible factor $1 \alpha .{ }^{* *} \mathrm{P}<0.01,{ }^{* * *} \mathrm{P}<0.001$ vs. scramble/vehicle group; ${ }^{\# \#} \mathrm{P}<0.01 \mathrm{vs}$. DMOG group; ${ }^{\$ \$} \mathrm{P}<0.01 \mathrm{vs}$. IOX2 group.

reduced the increased expression levels of VEGF induced by AKT-P125/313A overexpression (Fig. 2A). The expression and activity of HIF- $1 \alpha$ is also reportedly enhanced by AKT signaling under both normoxic and hypoxic conditions $(26,27)$. In the present study, the overexpression of AKT-WT or AKT-P125/313A significantly increased the expression levels of HIF-1 $\alpha$ from isolated nuclear extracts compared with the vector group (Fig. 2A). Moreover, vitamin $\mathrm{C}$ significantly weakened the increased expression levels of HIF-1 $\alpha$ induced by AKT-WT or AKT-P125/313A overexpression (Fig. 2A). Moreover, vitamin C was demonstrated to significantly decrease the expression levels of pT308-AKT compared with the vehicle-treated HLE-B3 cells (Fig. 2B). An immunoprecipitation assay was subsequently performed using a human AKT antibody to isolate endogenous AKT in HLE-B3 cells. It was observed that vitamin C treatment significantly increased the prolyl hydroxylation of AKT compared with the vehicle treated cells (Fig. 2C). Collectively, these findings suggested that vitamin $\mathrm{C}$ may suppress AKT kinase activity by enhancing the prolyl hydroxylation of AKT.
Inhibition of PHD2 increases VEGF expression levels. To further investigate the mechanism via which vitamin $\mathrm{C}$ regulates VEGF expression levels, the present study used three PHDs inhibitors (DMOG, IOX2 and Molidustat) to investigate their effects on the expression levels of VEGF. All of these inhibitors were found to significantly increase the expression levels of VEGF compared with the vehicle treated cells (Fig. 3A); the PHD2 specific inhibitor IOX2 exhibited the most significant effect at both the mRNA and protein expression level compared with the non-selective inhibitors DMOG and Molidustat (Fig. 3A). A PHD2 stable genetic knockdown model was subsequently established in HLE-B3 cells (Fig. 3B) and increased expression levels of HIF-1 $\alpha$ were observed in the stable PHD2 knockdown HLE-B3 cells (both sh1 and sh2) compared with the scramble control-transfected cells (Fig. 3B). Furthermore, the genetic knockdown of PHD2 significantly increased the expression levels of VEGF compared with the scramble group (Fig. 3C); however, there were no significant differences in the expression levels of VEGF and HIF-1 $\alpha$ in PHD2 knockdown HLE-B3 cells treated with the PHD2 specific inhibitor IOX2 

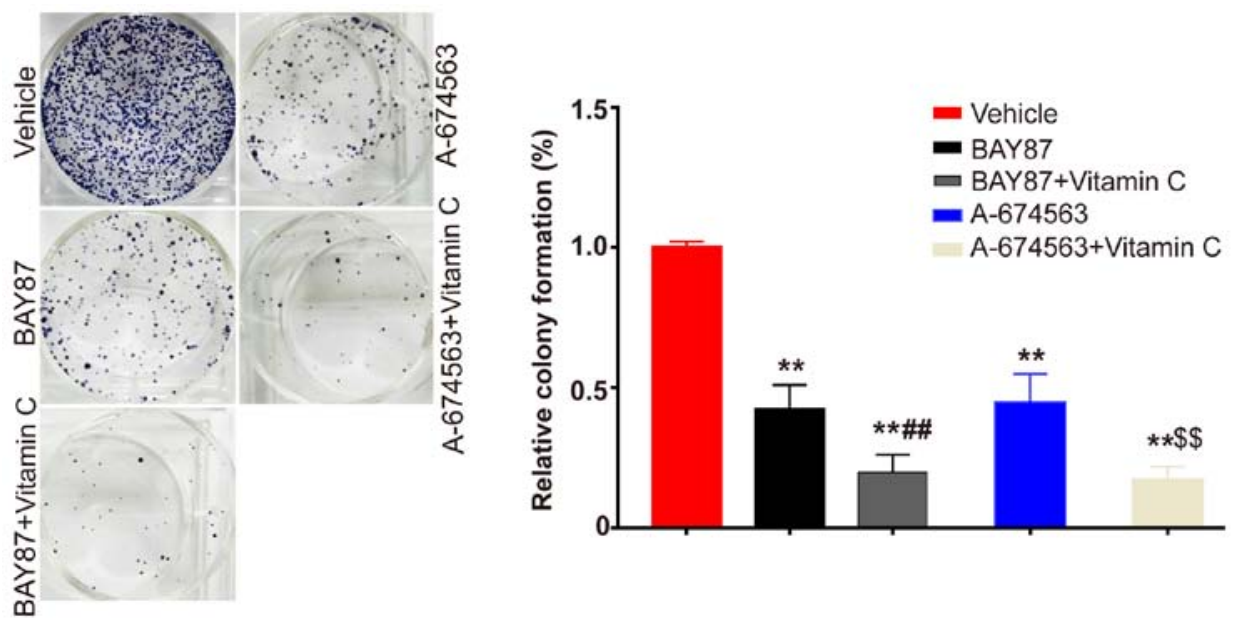

Figure 4. Synergistic effects of vitamin C treatment with AKT and HIF-1 $\alpha$ inhibitors on the proliferation of HLE-B3 cells. Colony formation assays were performed to determine the proliferation of HLE-B3 cells treated with vehicle (DMSO), $100 \mathrm{nM}$ BAY 87, $100 \mathrm{nM}$ BAY 87 and $100 \mu \mathrm{M}$ vitamin C, $5 \mu \mathrm{M}$ A- 674563 or $5 \mu \mathrm{M} \mathrm{A}-674563$ and $100 \mu \mathrm{M}$ vitamin C. Data are presented as the mean \pm SD of 3 independent experiments. HIF-1 $\alpha$, hypoxia inducible factor $1 \alpha$; BAT 87, BAY $87-2243 .{ }^{* * *} \mathrm{P}<0.01$ vs. vehicle group; ${ }^{\#} \mathrm{P}<0.01$ vs. BAY87 group; ${ }^{\$ \$} \mathrm{P}<0.01$ vs. A-674563 group.

A
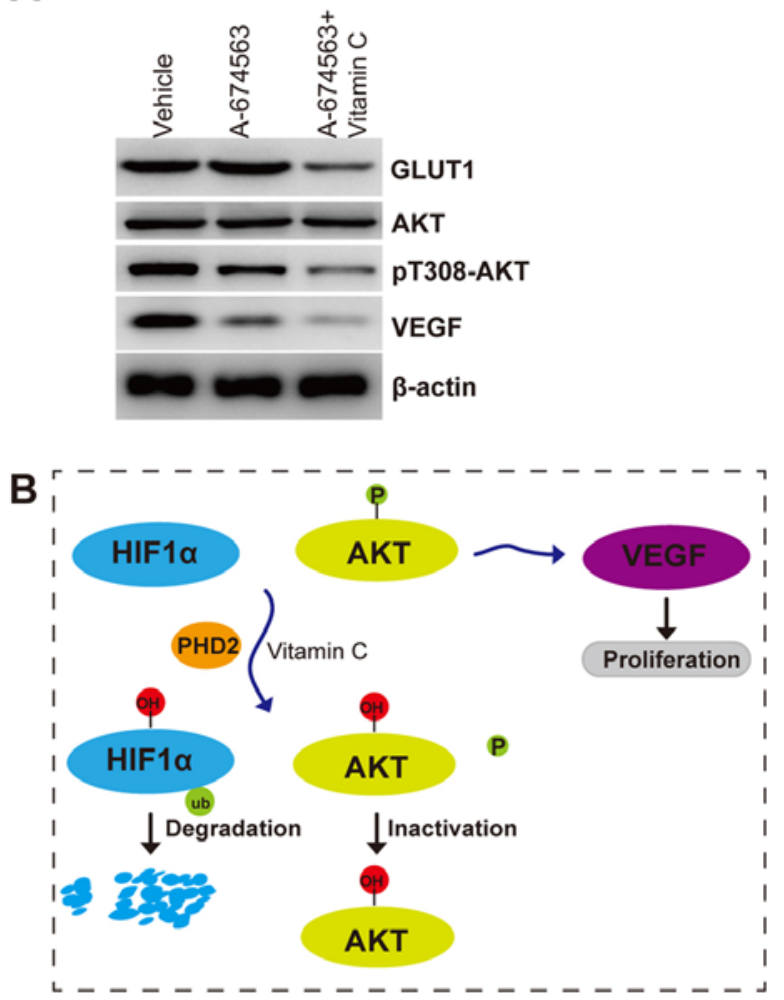
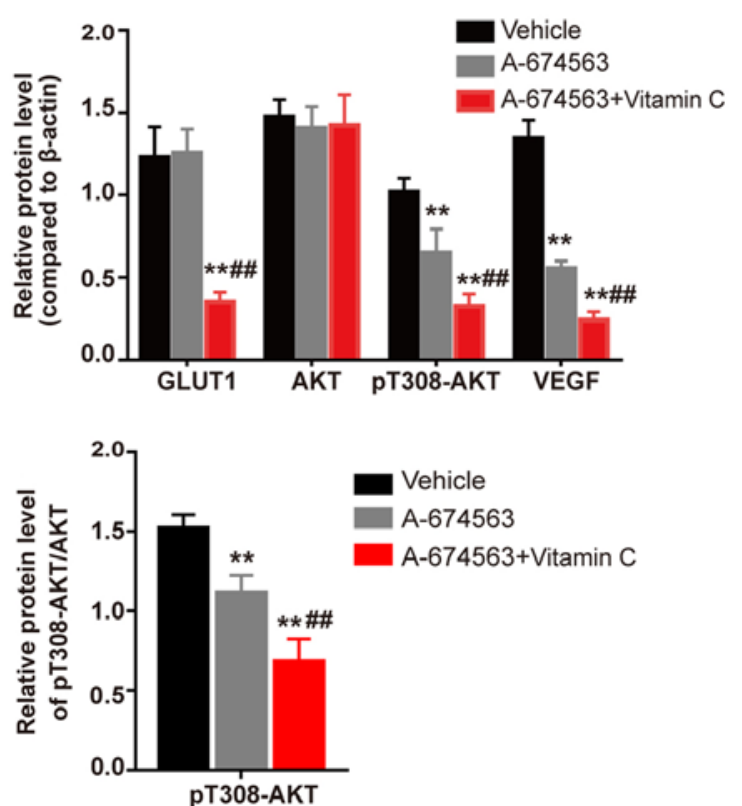

Figure 5. Synergistic effect of vitamin C treatment with AKT inhibitors on VEGF expression levels in HLE-B3 cells. (A) Expression levels of GLUT1, AKT, pT308-AKT and VEGF were analyzed using western blotting in HLE-B3 cells treated with vehicle (DMSO), $5 \mu \mathrm{M}$ A-674563 or $5 \mu \mathrm{M}$ A-674563 and $100 \mu \mathrm{M}$ vitamin $\mathrm{C}$ for $12 \mathrm{~h}$. Data are presented as the mean $\pm \mathrm{SD}$ of 3 independent experiments. (B) Schematic diagram of the hypothesized regulatory mechanism of vitamin C over VEGF expression levels through HIF-1 $\alpha$ dependent and AKT dependent ways. VEGF, vascular endothelial growth factor; GLUT1, glucose transporter 1; pT308-, phosphorylated on Tyrosine 308; HIF-1 $\alpha$, hypoxia inducible factor $1 \alpha$; PHD2, prolyl hydroxylase $2 .{ }^{* *} \mathrm{P}<0.01 \mathrm{vs}$. vehicle group; ${ }^{* \#} \mathrm{P}<0.01$ vs. A-674563 group.

compared with the scramble IOX2-treated cells (Fig. 3C). PHD2 is responsible for the proline hydroxylation of AKT and hence inhibits the activation of AKT (25). These findings were consistent with the hypothesis that vitamin $\mathrm{C}$ inhibits AKT kinase activity by enhancing the prolyl hydroxylation of AKT.
Synergistic effects of vitamin C with AKT inhibition or HIF-1 inhibition. The present study indicated that vitamin $C$ may enhance the prolyl hydroxylation of HIF-1 $\alpha$ to promote its degradation and the prolyl hydroxylation of AKT to suppress its activity. Thus, it was subsequently investigated whether vitamin C had synergistic effects with HIF-1 $\alpha$ or AKT 
inhibition. The selective AKT inhibitor A-674563 was used to compare the effects with vitamin C and HIF-1 inhibition. The colony formation assay results demonstrated that vitamin $\mathrm{C}$ had synergistic effects with a HIF-1 inhibitor (BAY 87-2243) and AKT inhibitor (A-674563); the combined treatment of each inhibitor with vitamin $\mathrm{C}$ significantly inhibited the proliferation of HLE-B3 cells to a greater extent compared with the inhibitor treatment alone (Fig. 4). To further demonstrate that vitamin $\mathrm{C}$ functions via HIF-1 $\alpha$ dependent and AKT dependent pathways to inhibit VEGF expression levels in LECs, western blotting was used to determine the effect of the AKT inhibitor on the expression levels of the HIF-1 $\alpha$ target protein GLUT1. It was discovered that the AKT inhibitor significantly inhibited the phosphorylation status of AKT and the expression levels of VEGF compared with the vehicle treated cells (Fig. 5A). Meanwhile, no significant differences were observed in the expression levels of the HIF-1 $\alpha$ target protein GLUT1 between the cells treated with the AKT inhibitor or the vehicle control. Notably, it was demonstrated that vitamin C treatment significantly inhibited the phosphorylation status of AKT and the expression levels of VEGF and GLUT1 in the presence of the AKT inhibitor compared with AKT inhibitor treated group (Fig. 5A). In conclusion, these findings suggested that vitamin $\mathrm{C}$ may inhibit the expression levels of VEGF via HIF-1 $\alpha$ and AKT dependent pathways in LECs. Hence, vitamin $\mathrm{C}$ was found to act synergistically with the HIF-1 or AKT inhibitor to inhibit the proliferation of LECs (Fig. 5B).

\section{Discussion}

PCO, the main complication after cataract surgery, is a leading cause of visual impairment (1). The proliferation of residual LECs has been found to serve a critical role in PCO formation (28). Therefore, the inhibition of the proliferation of LECs may provide an important strategy for PCO prevention and treatment in clinical practice (29). It has been previously reported that high levels of vitamin $\mathrm{C}$ exert beneficial effects, such as preventing age-related cataracts or PCO formation following cataract surgery $(11,12)$.

The HIF-1 $\alpha /$ VEGF axis has been demonstrated to serve an important role in the stimulation of cell proliferation and migration $(30,31)$. The authors' previous study revealed that vitamin $\mathrm{C}$ inhibited the proliferation of human LECs by promoting the degradation of HIF-1 $\alpha$ via proline hydroxylation, which subsequently inhibited the expression of the HIF-1 $\alpha$ target gene VEGF (10). In the present study, it was found that vitamin $\mathrm{C}$ could further inhibit the proliferation of LECs and VEGF expression levels in LECs following HIF-1 inhibition. Moreover, the HIF-1 $\alpha$ target gene GLUT1 could not be regulated by vitamin $\mathrm{C}$ treatment following the treatment with the HIF-1 inhibitor BAY 87-2243. Thus, the present results suggested that vitamin $\mathrm{C}$ may suppress VEGF expression levels via both HIF-1 $\alpha$ dependent and independent manners. Indeed, it has been reported that AKT and HIF-1 $\alpha$ can independently regulate the expression levels of VEGF $(32,33)$. Moreover, a previous study also demonstrated that AKT and HIF-1 $\alpha$ independently enhanced cell proliferation (34). In the present study, vitamin $C$ also demonstrated synergistic inhibitory effects with the HIF-1 or AKT inhibitor over the proliferation of LECs.
Vitamin $\mathrm{C}$ serves as an electron-donor, maintaining the $\mathrm{Fe}$ iron in the ferrous $\left(\mathrm{Fe}^{2+}\right)$ state, which is necessary to achieve the full activity of prolyl-hydroxylase $(17,35)$. Vitamin C has been revealed to increase the degradation of HIF-1 $\alpha$ via proline hydroxylation $(10,36)$. Furthermore, PHDs were found to be responsible for the proline hydroxylation of HIF-1 $\alpha$ at proline residues 402 and 564 within the oxygen-dependent degradation domain $(37,38)$. AKT kinase activity is an important mediator of the upregulation of VEGF $(24,39)$. It has since been discovered that AKT can be prolyl hydroxylated by PHD2 and its activity was also found to be inhibited by proline-hydroxylation (25). Other previous studies have also supported our results and suggested that vitamin $C$ enhanced PHD2 hydroxylase activity (17,40-42). In the present study, it was demonstrated that the overexpression of AKT-WT increased the expression levels of VEGF. Moreover, vitamin $\mathrm{C}$ was revealed to prevent the AKT-WT-induced increases in VEGF expression levels. Furthermore, whilst the overexpression of hydroxylation-deficient mutants of AKT increased the expression levels of VEGF, vitamin $\mathrm{C}$ weakened its regulatory effect over AKT-induced VEGF expression. It was demonstrated that vitamin $\mathrm{C}$ inhibited AKT activity through decreasing the phosphorylation levels, which was followed by increased levels of proline hydroxylation of AKT. Moreover, the present results discovered that the PHD2 specific inhibitor IOX2 increased the protein and mRNA expression levels of VEGF to a higher extent compared with the non-selective inhibitors. It was also observed that the PHD2 knockdown reversed the regulation of IOX2 over VEGF expression levels in human LECs.

In conclusion, the findings of the present study demonstrated that the AKT inhibitor A-674653 inhibited the activity of AKT and the expression levels of VEGF but did not affect the expression levels of the HIF-1 $\alpha$ target protein GLUT1. Notably, the cotreatment of cells with vitamin C and the AKT inhibitor A-674563 reduced the phosphorylation status of AKT and the expression levels of VEGF compared with the A-674563 treatment alone. In addition, vitamin C exhibited synergistic effects with the HIF-1 inhibitor or AKT inhibitor to suppress the proliferation of human LECs. Therefore, the present study provided evidence to suggest that vitamin $\mathrm{C}$ may inhibit the expression levels of VEGF via HIF-1 $\alpha$ dependent and AKT dependent pathways in LECs. Thus, it is possible that vitamin $\mathrm{C}$ treatment may facilitate PCO prevention in clinical practice by inhibiting the proliferation of LECs.

\section{Acknowledgements}

Not applicable.

\section{Funding}

The present study was supported by the Key Program of Research and Development of Shaanxi, China (grant no. 2017SF-266).

\section{Availability of data and materials}

All data generated or analyzed during the present study are included in this published article. 


\section{Authors' contributions}

FW and LZ conceived and designed the study, acquired and analyzed the data and drafted the manuscript. LZ, YZ and LW contributed to the data analysis and experimental materials. JW and MY contributed to the design of the study and revised the manuscript. All authors read and approved the final manuscript.

\section{Ethics approval and consent to participate}

Not applicable.

\section{Patient consent for publication}

Not applicable.

\section{Competing interests}

The authors declare that they have no competing interests.

\section{References}

1. Raj SM, Vasavada AR, Johar SR, Vasavada VA and Vasavada VA Post-operative capsular opacification: A review. Int J Biomed Sci 3: 237-250, 2007.

2. Moulick PS, Rodrigues F and Shyamsundar K: Evaluation of posterior capsular opacification following phacoemulsification, extracapsular and small incision cataract surgery. Med J Armed Forces India 65: 225-228, 2009.

3. Duman R, Karel F, Özyol P and Ates C: Effect of four different intraocular lenses on posterior capsule opacification. Int $\mathrm{J}$ Ophthalmol 8: 118-121, 2015.

4. Zukin LM, Pedler MG, Groman-Lupa S, Pantcheva M, Ammar DA and Petrash JM: Aldose reductase inhibition prevents development of posterior capsular opacification in an in vivo model of cataract surgery. Invest Ophthalmol Vis Sci 59: 3591-3598, 2018.

5. Zhang C, Liu J, Jin N, Zhang G, Xi Y and Liu H: SiRNA targeting mTOR effectively prevents the proliferation and migration of human lens epithelial cells. PLoS One 11: e0167349, 2016.

6. Andjelić S, Drašlar K, Lumi X, Yan X, Graw J, Facskó A, Hawlina $M$ and Petrovski G: Morphological and proliferative studies on ex vivo cultured human anterior lens epithelial cells-relevance to capsular opacification. Acta Ophthalmol 93: e499-e506, 2015.

7. Abdelkader H, Alany RG and Pierscionek B: Age-related cataract and drug therapy: Opportunities and challenges for topical antioxidant delivery to the lens. J Pharm Pharmacol 67: 537-550, 2015.

8. Chang JR, Koo E, Agrón E, Hallak J, Clemons T, Azar D, Sperduto RD, Ferris FL III and Chew EY; Age-Related Eye Disease Study Group: Risk factors associated with incident cataracts and cataract surgery in the age-related eye disease study (AREDS): AREDS report number 32. Ophthalmology 118: 2113-2119, 2011.

9. Thiagarajan R and Manikandan R: Antioxidants and cataract. Free Radic Res 47: 337-345, 2013.

10. Zhao L, Quan Y, Wang J, Wang F,Zheng Y and Zhou A: Vitamin C inhibit the proliferation, migration and epithelial-mesenchymaltransition of lens epithelial cells by destabilizing HIF-1 $\alpha$. Int J Clin Exp Med 8: 15155-15163, 2015.

11. Kaur A, Gupta V, Christopher AF, Malik MA and Bansal P: Nutraceuticals in prevention of cataract-An evidence based approach. Saudi J Ophthalmol 31: 30-37, 2017.

12. Valero MP, Fletcher AE, De Stavola BL, Vioque J and Alepuz VC: Vitamin $C$ is associated with reduced risk of cataract in a mediterranean population. J Nutr 132: 1299-1306, 2002.

13. Yum S, Jeong S, Kim D, Lee S, Kim W, Yoo JW, Kim JA, Kwon OS, Kim DD, Min DS and Jung Y: Minoxidil induction of VEGF is mediated by inhibition of HIF-prolyl hydroxylase. Int $\mathrm{J}$ Mol Sci 19: pii: E53, 2017.
14. Zhang Y, Xu Y, Ma J, Pang X and Dong M: Adrenomedullin promotes angiogenesis in epithelial ovarian cancer through upregulating hypoxia-inducible factor- $1 \alpha$ and vascular endothelial growth factor. Sci Rep 7: 40524, 2017.

15. Takei A, Ekström M, Mammadzada P, Aronsson M, Yu M, Kvanta A and André H: Gene transfer of prolyl hydroxylase domain 2 inhibits hypoxia-inducible angiogenesis in a model of choroidal neovascularization. Sci Rep 7: 42546, 2017.

16. Xiong GF, Stewart RL, Chen J, Gao T, Scott TL, Samayoa LM, O'Connor K, Lane AN and Xu R: Collagen prolyl 4-hydroxylase 1 is essential for HIF-1 $\alpha$ stabilization and TNBC chemoresistance. Nat Commun 9: 4456, 2018.

17. Kuiper $\mathrm{C}$ and Vissers MC: Ascorbate as a co-factor for fe- and 2-oxoglutarate dependent dioxygenases: Physiological activity in tumor growth and progression. Front Oncol 4: 359, 2014.

18. Livak KJ and Schmittgen TD: Analysis of relative gene expression data using real-time quantitative PCR and the 2(-Delta Delta C(T)) method. Methods 25: 402-408, 2001.

19. Zhou L, Wang Y, Zhou M, Zhang Y, Wang P, Li X, Yang J, Wang $H$ and Ding Z: HOXA9 inhibits HIF-1 $\alpha$-mediated glycolysis through interacting with CRIP2 to repress cutaneous squamous cell carcinoma development. Nat Commun 9: 1480, 2018.

20. Carmeliet P, Dor Y, Herbert JM, Fukumura D, Brusselmans K, Dewerchin M, Neeman M, Bono F, Abramovitch R, Maxwell P, et al: Role of HIF-1alpha in hypoxia-mediated apoptosis, cell proliferation and tumour angiogenesis. Nature 394: 485-490, 1998.

21. Finley LW, Carracedo A, Lee J, Souza A, Egia A, Zhang J, Teruya-Feldstein J, Moreira PI, Cardoso SM, Clish CB, et al: SIRT3 opposes reprogramming of cancer cell metabolism through HIF1 $\alpha$ destabilization. Cancer Cell 19: 416-428, 2011.

22. Groulx I and Lee S: Oxygen-dependent ubiquitination and degradation of hypoxia-inducible factor requires nuclear-cytoplasmic trafficking of the von Hippel-Lindau tumor suppressor protein. Mol Cell Biol 22: 5319-5336, 2002.

23. Shiozaki A, Shen-Tu G, Bai X, Iitaka D, De Falco V, Santoro M, Keshavjee S and Liu M: XB130 mediates cancer cell proliferation and survival through multiple signaling events downstream of Akt. PLoS One 7: e43646, 2012.

24. Karar J and Maity A: PI3K/AKT/mTOR pathway in angiogenesis. Front Mol Neurosci 4: 51, 2011

25. Guo J, Chakraborty AA, Liu P, Gan W, Zheng X, Inuzuka H, Wang B, Zhang J, Zhang L, Yuan M, et al: pVHL suppresses kinase activity of Akt in a proline-hydroxylation-dependent manner. Science 353: 929-932, 2016.

26. Woo YM, Shin Y, Lee EJ, Lee S, Jeong SH, Kong HK, Park EY, Kim HK, Han J, Chang $M$ and Park JH: Inhibition of aerobic glycolysis represses Akt/mTOR/HIF-1 $\alpha$ axis and restores tamoxifen sensitivity in antiestrogen-resistant breast cancer cells PLoS One 10: e0132285, 2015.

27. Pore N, Jiang Z, Shu HK, Bernhard E, Kao GD and Maity A: Akt1 activation can augment hypoxia-inducible factor-1alpha expression by increasing protein translation through a mammalian target of rapamycin-independent pathway. Mol Cancer Res 4: 471-479, 2006.

28. Li JH, Wang NL and Wang JJ: Expression of matrix metalloproteinases of human lens epithelial cells in the cultured lens capsule bag. Eye (Lond) 22: 439-444, 2008.

29. Chandler HL, Barden CA, Lu P, Kusewitt DF and Colitz CM: Prevention of posterior capsular opacification through cyclooxygenase-2 inhibition. Mol Vis 13: 677-691, 2007.

30. Shi GH and Zhou L: Emodin suppresses angiogenesis and metastasis in anaplastic thyroid cancer by affecting TRAF6-mediated pathways in vivo and in vitro. Mol Med Rep 18: 5191-5197, 2018.

31. Palazon A, Tyrakis PA, Macias D, Veliça P, Rundqvist $H$ Fitzpatrick S, Vojnovic N, Phan AT, Loman N, Hedenfalk I, et al: An HIF-1 $\alpha /$ VEGF-A axis in cytotoxic T cells regulates tumor progression. Cancer Cell 32: 669-683 e665.e5, 2017.

32. Zhang Z, Yao L, Yang J, Wang Z and Du G: PI3K/Akt and HIF-1 signaling pathway in hypoxia-ischemia (Review). Mol Med Rep 18: 3547-3554, 2018.

33. Choi SB, Park JB, Song TJ and Choi SY: Molecular mechanism of HIF-1-independent VEGF expression in a hepatocellular carcinoma cell line. Int J Mol Med 28: 449-454, 2011.

34. Arsham AM, Plas DR, Thompson CB and Simon MC: Akt and hypoxia-inducible factor-1 independently enhance tumor growth and angiogenesis. Cancer Res 64: 3500-3507, 2004. 
35. Satheesh NJ, Samuel SM and Busselberg D: Combination therapy with vitamin c could eradicate cancer stem cells. Biomolecules 10: pii: E79, 2020.

36. Fischer AP and Miles SL: Ascorbic acid, but not dehydroascorbic acid increases intracellular vitamin $\mathrm{C}$ content to decrease hypoxia inducible factor-1 alpha activity and reduce malignant potential in human melanoma. Biomed Pharmacother 86: 502-513, 2017.

37. Jaakkola P, Mole DR, Tian YM, Wilson M, Gielbert J, Gaskell SJ, von Kriegsheim A,Hebestreit HF, Mukherji M, Schofield CJ, et al: Targeting of HIF-alpha to the von Hippel-Lindau ubiquitylation complex by O2-regulated prolyl hydroxylation. Science 292: 468-472, 2001.

38. Marxsen JH, Stengel P, Doege K, Heikkinen P, Jokilehto T, Wagner T, Jelkmann W, Jaakkola P and Metzen E: Hypoxiainducible factor-1 (HIF-1) promotes its degradation by induction of HIF-alpha-prolyl-4-hydroxylases. Biochem J 381: 761-767, 2004.

39. Kawasaki Y, Fujiki M, Uchida S, Morishige M, Momii Y and Ishii K: A single oral dose of geranylgeranylacetone upregulates vascular endothelial growth factor and protects against kainic acid-induced neuronal cell death: Involvement of the phosphatidylinositol-3 kinase/akt pathway. Pathobiology 84: 184-191, 2017.
40. Lindsey RC, Cheng S and Mohan S: Vitamin C effects on 5-hydroxymethylcytosine and gene expression in osteoblasts and chondrocytes: Potential involvement of PHD2. PLoS One 14: e0220653, 2019.

41. Xing W, Pourteymoor S and Mohan S: Ascorbic acid regulates osterix expression in osteoblasts by activation of prolyl hydroxylase and ubiquitination-mediated proteosomal degradation pathway. Physiol Genomics 43: 749-757, 2011.

42. Lee HY, Lee T, Lee N, Yang EG, Lee C, Lee J, Moon EY, Ha J and Park H: Src activates HIF-1 $\alpha$ not through direct phosphorylation of HIF-1 $\alpha$ specific prolyl-4 hydroxylase 2 but through activation of the NADPH oxidase/Rac pathway. Carcinogenesis 32: 703-712, 2011.

This work is licensed under a Creative Commons Attribution-NonCommercial-NoDerivatives 4.0 International (CC BY-NC-ND 4.0) License. 